\title{
FURTHER EVIDENCE OF CENTRAL MUSCLE RELAXANT ACTIVITY OF IMIPRAMINE, DESMETHYLIMIPRAMINE AND AMITRIPTYLINE
}

\author{
J.N. SINHA, B.P. JAJU AND R.C. SRIMAL* \\ Department of Pharmacology and Therapeutics, K.G. Medical College, Luckncw University, \\ Luckncw-3, India \\ Received for publication April 6, 1966
}

Hafliger (1) synthesized a series of iminodibenzyl compounds which were found to possess antihistaminic, anticholinergic, sedative and analgesic properties. It was only after a clinical trial by Kuhn (2) that G 22355 (imipramine) "emerged as an antidepressant". The exact mechanism of the antidepressant action of imipraminc (IMI), its derivative desmethylimipramine (DMI) and its analogue amitriptyline (AMI) is not yet established. These agents have been shown to antagonise reserpine induced muscular rigidity and this effect has been attributed to their central cholinolytic activity $(3,4)$. Another structurally related antidepressant, orphenadrine, has been reported to possess both central (5) and peripheral (6) muscle relaxant properties. We have, earlier, reported the inhibition of myoneural transmissson by IMI, DMI and AMI (7). Prolonged inhibition of linguomandibular reflex by low doses of these agents as compared to short lived action of mephenesin (8) prompted us to find out if these agents fulfill all the criteria essential for a central muscle relaxant. Accordingly, these drugs were subjected to various test procedures like effect on behaviour, effect on polysynaptic linguomandibular reflex, effect on facilitatory influence of reticular formation on patellar reflex and the effect on decerebrate muscular rigidity in cat.

\section{METHODS}

The present investigation was carried out in 12 rabbits $(1.0-1.5 \mathrm{~kg}$ ) and 38 adult cats $(2.6-4.5 \mathrm{~kg}$ ) irrespective of their sex. During experiments in anaesthetised animal, vagi were cut as a routine and animal maintained on artificial positive pressure respiration. Blood pressure was recorded from a common carotid artery through a mercury manometer and a polythene tube was passed in a femoral vein.

Behavioral studies were carried out in rabbits. The drugs were injected intravenously and animals observed for three hours.

Polysynaptic linguomandibular reflex (LMR) was elicited in cat, under pentobarbitone (35 $\mathrm{mg} / \mathrm{kg}$ i.p.) anaesthesia, by stimulating (2-4 V,5-10 $\mathrm{msec}$ duration, 1 shock/ $/ \mathrm{sec})$ the root

* Present address : Pharmacology Division, Central Drug Research Institute, Chatter Manzil Palace, Lucknow, India. 
of the tongue according to the technique of King and Unna (9). Movement of the lower jaw was recorded through a system of pulleys on smoked kymograph paper. Drugs were injected into a lateral cerebral ventricle according to the technique of Feldberg and Sherwood (10). Contractions of the gastrocnemius muscle due to electrical stimulation of the sciatic nerve $(0.2-0.4 \mathrm{~V}, 1 \mathrm{msec}$ duration, 1 shock/sec) were used as control for peripheral neuromuscular transmission.

Monosynaptic patellar reflex and its facilitation duc to electrical stimulation of the bulbar reticular formation was elicited in cat anaesthetised with ether and maintained on chloralose $(60 \mathrm{mg} / \mathrm{kg}$ i.v.). The quadriceps tendon was tapped every 5 seconds by means of an electromagnetic hammer and movement of the limb was recorded through a system of pulleys on kymograph (11). Polysynaptic facilitation of the reflex was obtained by stereotaxically stimulating $(2-6 \mathrm{~V}, 1-2 \mathrm{msec}$ duration, $100 \mathrm{shocks} / \mathrm{sec})$ the dorsolateral facilitatory area of reticular formation for 15 seconds using a concentric bipolar needle clectrode. The electrode placement was aided by the parameters described by Henneman et al. (12).

All stimuli were derived from a Grass model S4 electronic stimulator delivering rectangular pulses.

Decerebrate rigidity in cat was induced by making a mid-collicular section under ether anaesthesia. Patellar reflex was recorded at the same time. Ether was stopped after decerebration and the drug was injected intravenously.

RESULTS

\section{A. Studies on gross behaviour of rabbits}

Effect of intravenous IMI, DMI and AMI was studied on the gross behaviour of rabbits with particular reference to their motor activity. IMI in doses of 2.0 to $5.0 \mathrm{mg} /$ $\mathrm{kg}$ i.v. induced sedation and retarded motor activity whereas higher doses (5.0 to 10.0 $\mathrm{mg} / \mathrm{kg}$ i.v.), in addition, produced relaxation of abdominal muscles and hind limb paralysis without concommitant head drop or loss of consciousness. The hind limb paralysis lasted about two and a half hours. Effects similar to IMI $(2-5 \mathrm{mg} / \mathrm{kg})$ were produced by DMI (4-8 $\mathrm{mg} / \mathrm{kg}$ i.v.) and AMI $(2-4 \mathrm{mg} / \mathrm{kg}$ i.v.). Further higher doses of DMI (8-12 $\mathrm{mg} / \mathrm{kg}$ i.v.) and of AMI (4-8 $\mathrm{mg} / \mathrm{kg}$ i.v.) caused relaxation of abdominal muscles and hind limb paralysis without head drop or loss of consciousness. Loss of righting reflex by these drugs was not observed even in doses upto $15 \mathrm{mg} / \mathrm{kg}$ i.v. Still higher dose produced convulsions and were usually fatal.

\section{B. Effect on linguomandibular polysynaptic reflex (LMR)}

Effect of intracerebroventricular injection (i.c.v.) of IMI, DMI and AMI was studied on linguomandibular reflex and compared with mephenesin administered by the same route. Mephenesin (1.25 mg i.c.v.) produced about $50 \%$ inhibition of LMR and the recovery occurred in about 15 minutes. IMI in dose of $0.25 \mathrm{mg}$ i.c.v. also inhibited the LMR to the same extent and the recovery was observed after 45 minutes. Peripheral control of neuromuscular transmission in sciatic nerve-gastrocnemius preparation remain- 
A
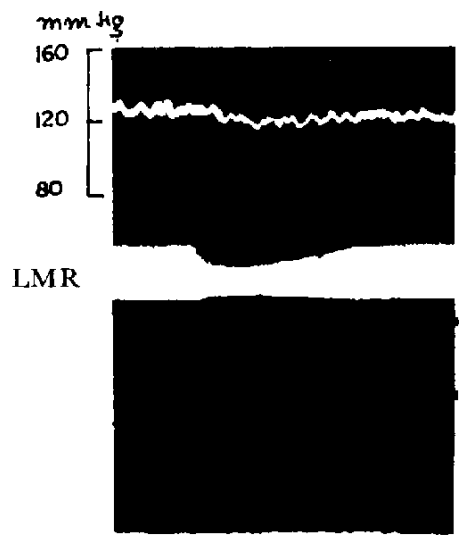

\section{SGM}

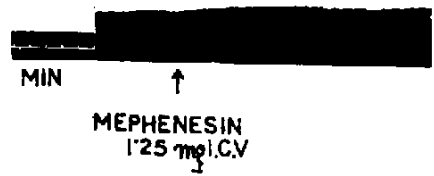

B
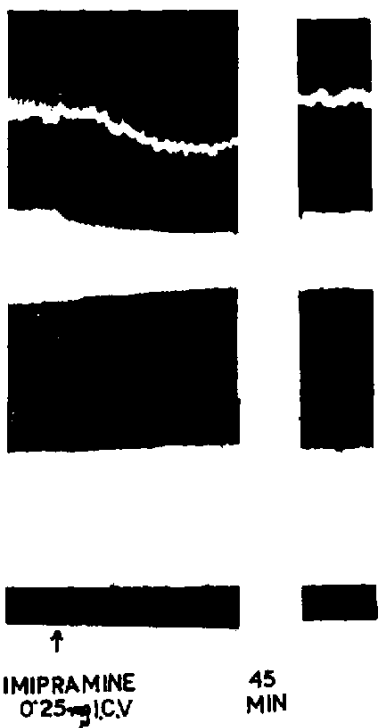

FIG. 1. Shows responses of blood pressure, linguomandibular reflex (LMR) and sciatic nerve stimulated contractions of gastrocnemius muscle (SGM) in cats. (A) shows inhibition of LMR by mephenesin (1.25 mg i.c.v.) with quick recovery. (B) shows a similar effect of irnipramine $(0.25 \mathrm{mg}$ i.c.v.) on LMR, with a long duration of action (45 minutes). Note that SGM remained unaffected.

TABLE 1. Central muscle relaxant activity of imipramine, desmethylimipramine and amitriptyline.

\begin{tabular}{lccc}
\hline \multicolumn{1}{c}{ Drug } & ED50 (mg) + S.E. & $95 \%$ Confidence limits & Activity ratio \\
\cline { 2 - 3 } Mephenesin & $1.25 \pm 0.01$ & $1.27-1.23$ & 1 \\
Imipramine & $0.24 \pm 0.02$ & $0.27-0.21$ & 5.20 \\
Desmethylimipramine & $0.56 \pm 0.20$ & $0.95-0.17$ & 2.23 \\
Amitriptyline & $0.40 \pm 0.002$ & $0.41-0.39$ & 3.12 \\
\hline
\end{tabular}

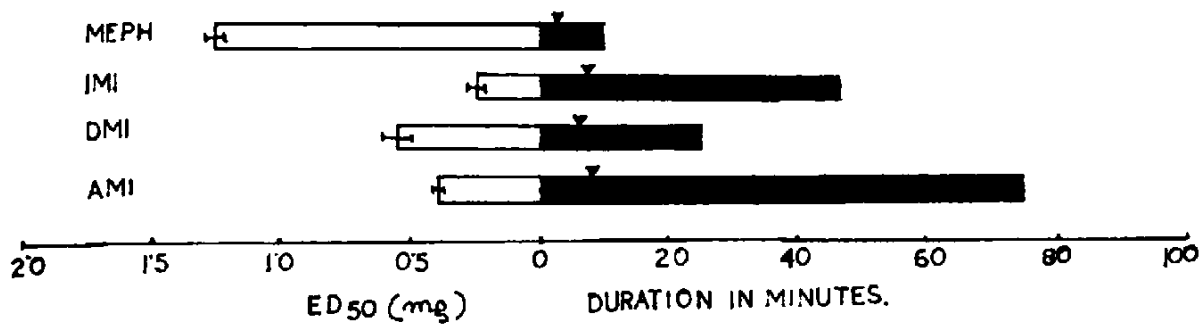

FIG. 2. Central muscle relaxant activity of imipramine and allied drugs compared with mephenesin. The ED50 (mg) and standard error is shown on the left and the duration of action (minutes) is shown on the right. The time of onset of peak effect is indicated by the triangles on the bar. Imipramine was most potent and had long duration of action. Mephenesin was the least potent and had minimum duration of action. 


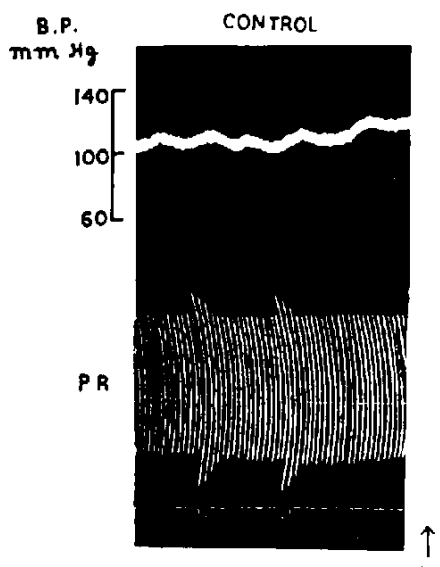

$15 \mathrm{MIN}$

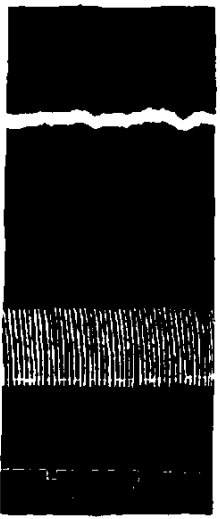

IMIPR AMINE

$1.25 \%$ TOPICAL

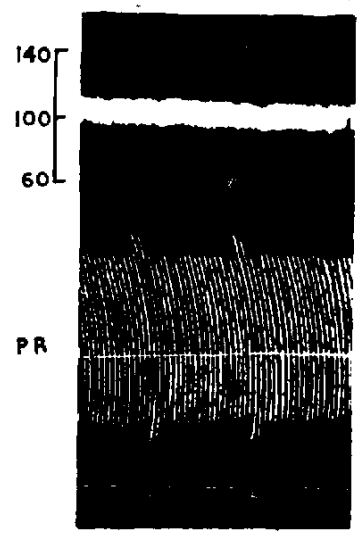

DMI

$20 \%$

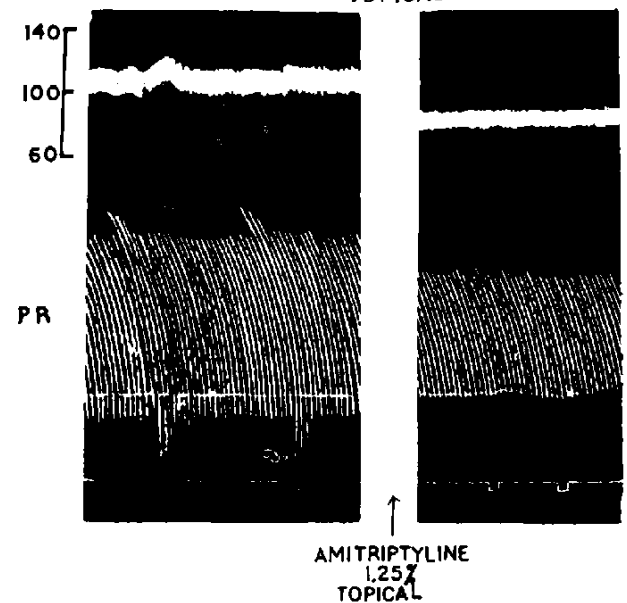

TOPICAL
$200 \mathrm{MN}$
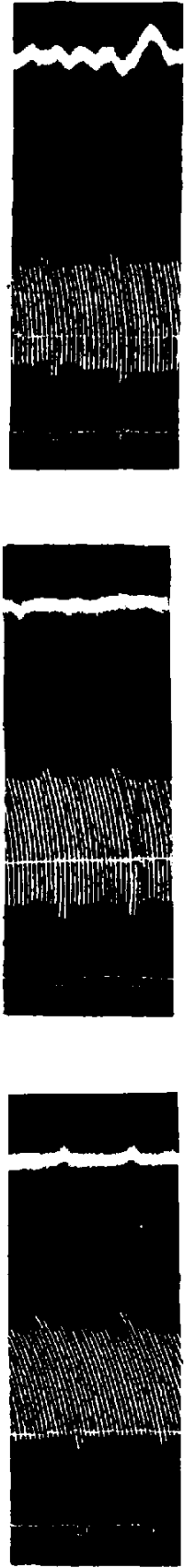

FIG. 3. Effect of topical application of imipramine-1.25\% (upper panels), desmethylimipramine-2.0\% (middle panels) and amitriptyline-1.25\% (lower panels) to the calamus scriptorius on the blood pressure (upper tracing in all the panels) and patellar reflex (PR). PR was elicited by tapping the quadriceps tendon by means of an electromagnetic hammer every 5 seconds and its facilitation was obtained by clectrical stimulation (marked by signal) of the brainstem reticular formation (rectangular pulses of $2.0 \mathrm{~V}, 1 \mathrm{msec}$ duration and $100 / \mathrm{sec}$ frequency). Note the peak effect at 15 minutes (middle panels) and partial recovery at 200 minutes. 
ed anaffected (see Fig. 1). DMI and AMI, similarly, also caused inhibition of the LMR. The activity ratio of these compounds, taking mephenesin as one (see Table 1) revealed that IMI was 5.20 times as potent as mephenesin while DMI and AMI were 2.23 and 3.12 times more potent than mephenesin. Fig. 2 is a graphical representation of ED50, standard error, duration of action (at ED50 dose level) of each drug. All the drugs produced their maximum effect on LMR within 8 minutes. IMI produced its peak
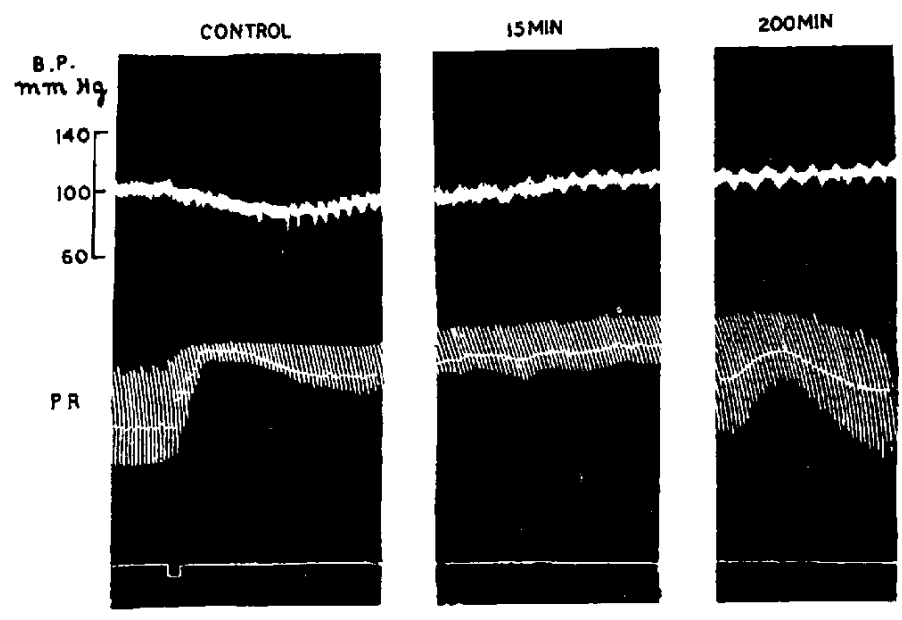

MID BRAIN

SECTION
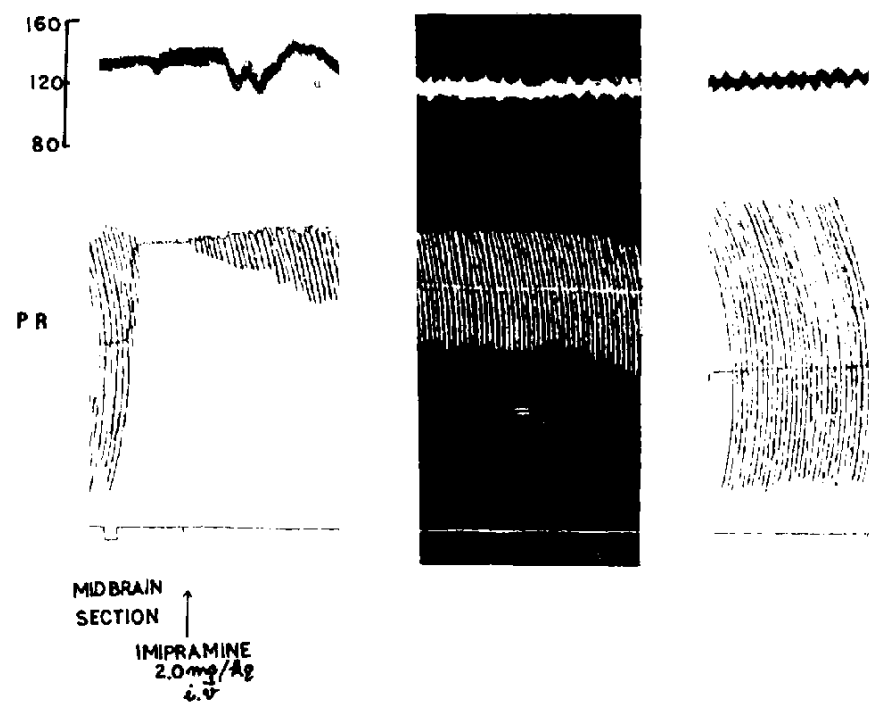

FIC. 4. Record of patellar reflex in two different cats. Upper panels show the effect of time on decercbrate rigidity. Mid-collicular section was performed manually (marked by signal). Note immediate decrease in amplitude of patellar reflex and marked increase in tone. Recovery of the amplitude occurred at 200 minutes but the muscle tone was still high. Lower panels show the effect of imipramine ( $2 \mathrm{mg} / \mathrm{kg}$ i.v.) on decerebrate rigidity. Notc immediate effect of the drug on patellar reflex (PR). At 15 minutes recovery $w$ as partial but at 200 minutes tone and amplitude had returned to normal level. 
effect in 7 minutes and the effect persisted upto 46 minutes. AMI, though less potent than IMI had the longest duration of action (75 minutes). DMI came out to be the least potent.

C. Effect on polysynaptic facilitation of monosynaptic patellar reflex (PR)

Polysynaptic facilitation of the patellar reflex (PR) was obtained by stimulation of a facilitatory area of brainstem reticular formation $(2-6 \mathrm{~V}, 100$ shocks/sec of $1-2 \mathrm{msec}$ duration for 15 seconds). Fig. 3 shows the typical effects of topical application of IMI $(1.25 \%)$, DMI (2.0\%) and AMI (1.25\%) on the PR itself and its reticular facilitation. All the three drugs decreased the amplitude of the PR and abolished the polysynaptic facilitation of this reflex. These effects were gradual in onset and the maximum effect was observed after 15 minutes. Partial recovery was observed after 200 minutes.

D. Effect on decerebrate muscular rigidity in cat

Muscular rigidity was obtained by manually sectioning the brainstem at the midcollicular level. At the height of this rigidity, intravenous administration of IMI $(2.0$ $\mathrm{mg} / \mathrm{kg})$, DMI $(2.5 \mathrm{mg} / \mathrm{kg})$ and AMI $(2.0 \mathrm{mg} / \mathrm{kg})$ counteracted the abnormal muscle tone. Fig. 4 demonstrates the gradual recovery from the decerebrate rigidity following intravenous injection of IMI $(2.0 \mathrm{mg} / \mathrm{kg})$. At 200 minutes muscle tone was even lower than the control level and amplitude of PR was also bigger. It is compared to a control experiment (upper panels) where no drug was given and the extent of the rigidity was observed for over three hours. In such an experiment after midcollicular section there was decrease in the amplitude of PR and marked increase in the muscle tone. Recovery of the muscle tone was not obtained even at 200 minutes although amplitude of PR practically returned to normal.

\section{DISGUSSION}

In the present study imipramine, desmethylimipramine and amitriptyline were found to satisfy several criteria considered to be necessary for an agent to be labelled a central muscle relaxant. Intravenous administration of these agents in conscious rabbits caused sedation, drowsiness, decreased motor activity, relaxation of abdominal muscles and reversible hind limb paralysis without head drop or loss of consciousness. Prolonged inhibition of linguomandibular reflex after intracerebroventricular injection of imipramine as compared to short lived action of mephenesin pointed to the distinct advantage of former over the latter agent as central muscle relaxant. The facilitation of the patellar reflex induced by stimulation of brainstem reticular formation was abolished by topical application of these agents at the calamus scriptorius. The amplitude of the patellar reflex was also decreased at the same time. Thus imipramine, desmethylimipramine and amitriptyline seem to inhibit the facilitatory synapses of the brainstem reticular formation. But the effect on the polysynaptic facilitation did not seem to be specific since monosynaptic patellar reflex was also depressed at the same time. Decercbrate rigidity in cat was antagonised by all the three agents which is an important property of central muscle relaxants. 
Our studies clearly demonstrate the potent central muscle relaxant activity of imipramine, desmetylimipramine and amitriptyline. Increased muscle tone is a common accompaniment of reserpine syndrome and is consistently present in patients of depressive psychosis. These agents antagonise the increased motor activity induced by reserpine (3). Clinically they are effective antidepressants. In vicw of the increased muscle tone in depressive states and the effective central muscle relaxant property of these agents, it seems probable that this property of these agents might be playing some role in their antidepressant action. A controlled clinical trial of imipramine and its congeners as central muscle relaxants in certain spastic musclar disorders seems warranted.

\section{SUMMARY}

Intravenous administration of imipramine, desmethylimipramine and amitriptyline in conscious rabbits produced sedation, hind limb paralysis and relaxation of abdominal muscles, without head drop or loss of consciousness. The polysynaptic linguomandibular reflex was depressed by intracerebroventricular administration of these agents. Facilitation of the patellar reflex induced by stimulation of the brainstem reticular formation was also blocked. Furthermore, they abolished the muscular rigidity induced by decerebration in cat. Thus these agents seem to fulfill the criteria of a central muscle relaxant and may prove of value in certain spastic muscular disorders.

Acknowledgement : Authors are grateful to M/S J.R. Geigy, Switzerland, for the gift of imipramine (Tofranil) and desmethylimipramine (Pertofran) and to $M / S$ Merck Sharp \& Dohme, U.S.A. for the supply of amitriptyline (Elavil).

\section{REFERENCES}

1) Hafi.lger, F. : Cand. Psych. Asso. J. 4, S69 (1959)

2) KuHN, R. : Schreeiz. med. Wschr. 87, 1135 (1957)

3) Sulser, F., Watts. J. AND Brodie, B.B. : Ann. N.Y. Acad. Sci. 96, 279 (1962)

4) Sulser, F., Bickev, M.H. ANo Brodie, B.B. : J. Pharmacol. 144, 321 (1964)

5) Bulasma, U.G., Harms, A.F., Funcke, A.B.H., Terstefge, H.M. and Nauta, W.T. : Atch. int. Pharmacodyn. 106, 332 (1956)

6) Onuaguluchi, G. And Lewis, J.J. : J. Pharm. Pharmacol. 15, 329 (1963)

7) Sinha, J.N., Dixit, K.S., Srimal, R.C., Chandra, O. And Bhargava, K.P. : Arch. int. Pharmacodyn. In press (1966)

8) Sinha, J.N., SRimal, R.C., Dixit, K.S., Cha.vira, O. and Bhargava, K.P. : This Journal. 16, $120(1966)$

9) King, E.E. AND Unn., K.R. : $J$. Pharmacol. 111, 293 (1954)

10) Feldberg, W. and Sherwood, S.L. : J. Physiol. 123, 148 (1954)

11) Calma, I. and Wright, S. : Ibid. 106, 211 (1947)

12) Henniman, E., Kaplan, A. and Unna, K. : J. Pharmacol. 97, 331 (1949) 